TEGAR 4 (1) (2020) 23-28

Journal of Teaching Physical Education in Elementary School

Available online at :

https://ejournal.upi.edu/index.php/tegar/article/view/28502

DOI: https://doi.org/10.17509/tegar.v4i1.28502

\title{
Fine and Gross Motor Skill Proficiency Differences of Children Aged 8-9 Years based on Gender
}

Ricky Wibowo, Didin Budiman, Gano Sumarno

Universitas Pendidikan Indonesia, Indonesia

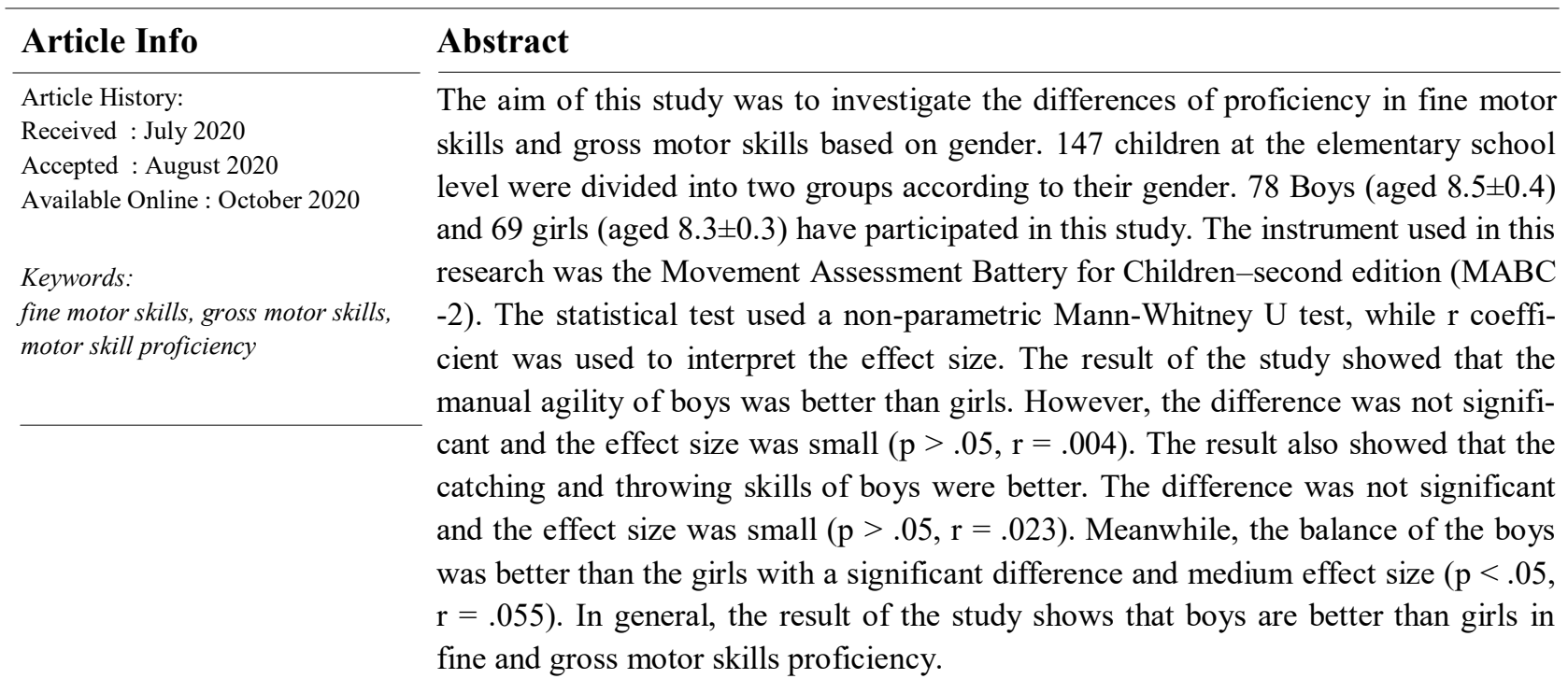




\section{INTRODUCTION}

The increase of sedentary behavior is a current global problem, although it is commonly known that active lifestyle gives various positive impacts. The lack of physical activity in the children will create a wide chance of obesity (Kumar \& Kelly, 2017). The important factor deciding children participation in physical activity is motor skill proficiency. The motor skill proficiency has a vital role on the involvement in physical activity (Stodden et al., 2008). long-term studies show that the higher the children proficiency in mastering motor skills, the higher the possibility of the children to move actively and is physically fitter in their adolescent and adulthood periods (Stodden et al., 2008: Barnett et al., 2009). Besides holding an important role in physical activity involvement, motor skill also has an important role in academic achievement success (Haapala, 2013). Another study shows that motor skill correlates with the physical activity level and physical fitness related to health (Cohen et al., 2014; Okely, et al. 2004). Motor skill has a positive relationship with physical fitness related to health, such as muscle strength and endurance, and a negative relationship with the adolescent body fat (Stodden et al. 2009).

Motor skill is also needed to participate in sports, games, and a long-life physical activity (Logan, et al. 2012). Calley (2010) reports that a person will be easier to involve in various physical activities if they have understood the basic movement level. According to the fact, motor skill becomes an interesting topic for the researcher to develop the motor skill. Developing motor skill and mastering gross motor skill are crucial for lower level elementary school students (Hardy et al., 2010). The skill is the infrastructure for them to learn sports, games, and complex physical activity skills in the future (Branta, 1984). Motor skill is divided into gross motor skill and fine motor skill. Gross motor skills require coordination of arms, legs, and other major parts of body to carry out acts, such as running, jumping, and throwing (HaibachBeach, Reid, \& Collier, 2011). Meanwhile, fine motor skills need a smaller movement coordination between fingers, hands, and feet to act, such as lifting and pressing a small object (Piek, Dawson, Smith, \& Gasson, 2008). The gross and fine motor skills are parts of growth and development since childhood which gradually get better by the age and movement experience based on their physical activities. Gross motor skill is the movement involving major muscle groups as the basic (Magil, 1990). Meanwhile, fine motor skill is the skill requiring controls from small body muscles to achieve the goal of the skill (Magil, 1990).

In previous research, the motor skill proficiency is affected by gender. Robinson (2011) reports that boys have better locomotor skills and object controls than girls. The research also found that boys performance was better due to their higher and regular involvement in sport activities. However, results of researches related motor skills are different. The result of a study showed that the motor skill of boys and girls is not different (Van Waelveld et al.,2008; Hardy et al., 2010). The object control skill tends to be similar according to gender (Pope, 2011; LeGear et al., 2012). However, another research states that boys are better in object control skills (Foulkes et al., 2015; Spessato et al., 2013). Differences also happen in locomotor skill, a research shows that the locomotor skill is similar (Foulkes et al., 2015; Spessato et al., 2013), a research shows that female children are better (Barnett et al., 2008; van Beurden et al., 2002), while another research shows that boys are better (Robinson, 2010). Another motor skill research shows that the boys and girls balance motor skill results are similar (Singh et al., 2015; Shala, 2009), while another research states that girls are better (Venetsanou \& Kambas, 2011; Livesey, 2007).

According to the distribution of the result of the study, the results were not consistent, although some of the researches have a similar result pattern. To answer the aforementioned issues, this research was aimed at comparing motor skill proficiency of boys and girls aged 8-9 years. Meanwhile, the test instrument used was MABC-2. This test is one of valid and reliable test instruments to measure fine and gross motor skills (Whyatt \& Craig, 2012; Liu $\&$ Breslin, 2013). The strength of MABC-2 is that it could measure the fine and gross motor skill of 3-16year age range (Brown \& Lalor, 2009). The MABC2 instrument covers manual dexterity, catching and aiming, and balance skills.

\section{METHOD}

\section{Participant}

Participants of the study were 147 elementary school children aged 8-9 years in Bandung City, Indonesia. The samples were chosen according to the class (quota sample) as the part of the population. The samples consisted of 78 boys (aged $8.5 \pm 0.4$ ) and 69 girls (aged $8.3 \pm 0.3$ ). Before the data 
collection process, the researcher has conducted a coordination with Physical Education teachers to get consent forms from the parents.

\section{Measurement}

To measure the gross and fine motor skills, the instrument used was MABC-2 (Movement Assessment Battery for Children-2) (Henderson et al., 2007). The age group used was band 2 for age 7-10 years. The test consisted of 8 movement tasks divided into three components, including the manual dexterity (the fine motor skill), catching and aiming, and balance (gross motor skill). The first motor skill was the manual dexterity consisting of placing pegs, threading lace, and drawing trail age. The second stage was aiming and catching consisting of catching with two hands and throwing beanbag onto mat. The third skill test was the balance test consisting of oneboard balance, walking heel to toe forwards, and hopping on mats. The test was administered by five persons and two Physical Education, Sport, and Health teachers. Before administering the test, the researcher had given an explanation and training directly to the assessing team and a prior test trial. The test was conducted in the school field with floor as the base. The test was conducted one by one by the assessing team. Data were taken during the Physical Education instruction, thus the participants had been ready with their sport attires and shoes. Before conducting the test, the participants received an explanation and direct demonstration of each motor test movement by the assessing team. The team assured that every participant understood each demonstrated movement.

\section{Data Analysis}

After gaining raw scores from the measurement, the scores were then derived into the standard score and percentile. The percentile scores were then used to compare the motor skill proficiency of male and female children. Before conducting the parametric test, the normality test and homogeneity test were conducted by using one-sample kolmogorov-smirnov test for normality test and levene's test for testing the homogeneity. According to the normality test, the data were not normally distributed $<.05$. Therefore, a non-parametric Mann-Whitney U test $(\mathrm{p}<.05)$ was used to find out the result differences of motor skill proficiency of male and female children. To examine the significance statistically, the $r$ coefficient was used to interpret the effect size. The effect is small if $\mathrm{r}<0.3$, the effect is moderate if $\mathrm{r}$ is in the range $0.3-$
0.5 , and the effect is high if $\mathrm{r}>0.5$ (Fritz et al., 2012). The statistical analysis used IBM SPSS Statistic version 22 software.

\section{RESULT}

Table 1 shows the characteristic description of manual dexterity, catching and aiming, balance, and the total score. In the manual dexterity, boys were better than girls, but the difference was not significant and had a small effect size $(p>.05, r=.004)$. Similar with manual dexterity, boys were better in catching and aiming, but the difference was not significant and had a small effect size $(\mathrm{p}>.05, \mathrm{r}$ $=.023$ ). Meanwhile, in balance proficiency, boys were better than girls. The difference was statistically significant and had a medium effect size $(\mathrm{p}<.05$, $\mathrm{r}=.055)$. In general, from three skill tests, statistical data show that boys outperformed girls significantly with a medium effect size $(p>.05, r=.033)$.

Table 1. Description of Motor Skill Characteristics based on Gender

\begin{tabular}{lcccccc}
\hline & $\mathrm{n}$ & $\mathrm{M}$ & $\mathrm{SD}$ & Med. & $p$ & $r$ \\
\hline Manual & & & & & & \\
Dexterity & & & & & & \\
$\quad$ Boys & 78 & 5.38 & 5.05 & 5 & .438 & $.004^{+}$ \\
$\quad$ Girls & 69 & 6.2 & 4.7 & 5 & & \\
Catching & & & & & & \\
and Aiming & & & & & & \\
$\quad$ Boys & 78 & 48.4 & 30.2 & 50 & .069 & $.023^{+}$ \\
$\quad$ Girls & 69 & 39.2 & 20.2 & 50 & & \\
Balance & & & & & & \\
Boys & 78 & 36 & 8.52 & 37 & $.005^{*}$ & $.055^{++}$ \\
$\quad$ Girls & 69 & 31.5 & 8.6 & 37 & & \\
Total & & & & & & \\
$\quad$ Boys & 78 & 65.3 & 7.46 & 65.5 & $.031^{*}$ & $.033^{++}$ \\
$\quad$ Girls & 69 & 62.5 & 7.05 & 62 & & \\
\hline
\end{tabular}

Note:

$\mathrm{n}=$ total sample; $\mathrm{M}=$ mean; $\mathrm{SD}=$ standard deviation; $\mathrm{p}=$ value Mann-Whitney $\mathrm{U}$ test; $\mathrm{r}=$ effect size; $*=$ significance $(\mathrm{p}<0.05) ;{ }^{+}=$small effect size ${ }^{++}=$moderate effect size

Figure 1 shows the characteristics and distribution of manual dexterity, catching and aiming, balance, and the total score data. In the manual dexterity data, boys and girls had distribution range data and outlier data that were almost similar which mean that the data of manual dexterity had a high range. Meanwhile, in catching and aiming, the variance of the data was fairly high with higher median and maximum scores of male children. The balance skill data showed that the variance and median of both groups were almost the same. Although the girls had higher minimum scores than boys, some boys had higher maximum scores than the girls. In general, it 
shows that boys group outperformed girls group (Van Waelveld et al.,2008).

\section{DISCUSSION}

The aim of the research was to find out the motor skill differences between boys group and girls group aged 8-9 years by using MABC-2 test. The research showed that the boys group was superior from girls group. From eight test items divided into three test categories, including manual dexterity, catching and aiming, and balance skills, boys statistically significantly outperformed gils with a moderate effect size. The significant difference was found

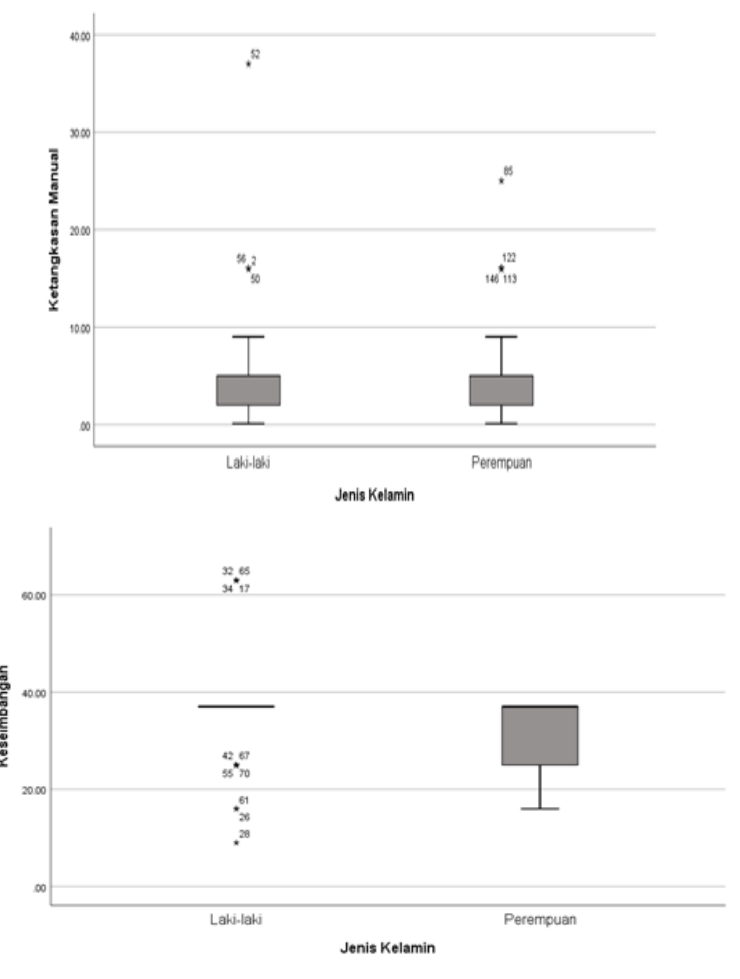

than the girls, but the difference was not significant (Van Waelveld et al.,2008). Meanwhile, in catching and aiming, the male children group outperformed with an insignificant difference. It might be because male children tend to enjoy ball games (Badrić, et al. 2015), thus their experiences in the games affected their catching and aiming performances. This result is relevant to the previous research of (Kokštejn et al., 2017; Spessato et al., 2013). The significant difference was found in balance. Boys group showed a significant difference compared to the girls group. Boys spend their time in various sport games, such as ball games and activities involving major mus

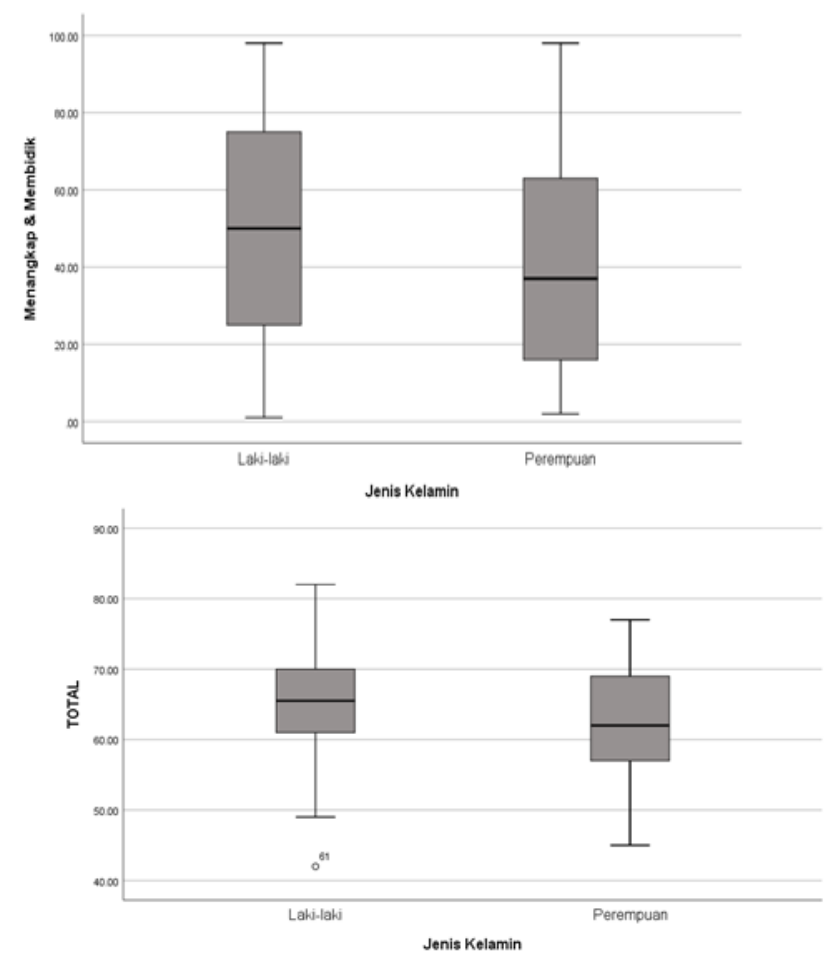

Figure 1. Characteristics and Distribution of MABC-2 Motor Skill Test Data

in the balance test, while the manual dexterity and catching and aiming of male children were higher with insignificant differences and small effect sizes.

Although boys and girls groups were different in the manual dexterity performance, the result was not significant. It shows that the fine motor skill of both groups was not significantly different with a small effect size. It might be caused by the fine motor skill activities experienced by the children before. The fine motor skill, such as drawing, writing, coloring, sewing, folding, and other activities, are attained in the preschool level until elementary school level. This result supports the previous research that the manual dexterity of boys was better cles, namely playing ball that would affect the balance skill difference. Meanwhile, most of female girls like art activities, language learning, and various fine motor skills (Pate, et al., 2004).

\section{CONCLUSION}

This research shows that boys had better fine and gross motor skills than the girls aged 8-9 years. The significant effect and moderate effect size were found on the balance component. Meanwhile, in the manual dexterity, catching, and aiming components, the effect sizes were small. 


\section{REFERENCES}

Barnett, L.M., van Beurden, E., Morgan, P.J., Brooks, L.O., Zask, A., \& Beard, J.R. (2009). Six Year Follow-up of Students who Participated in a School-based Physical Activity Intervention: A Longitudinal Cohort Study. International Journal of Behavioral Nutrition and Physical Activity, 6(48). doi : 10.1186/14795868-6-48.

Barnett, L. M., Morgan, P. J., van Beurden, E., \& Beard, J. R. (2008). Perceived Sports Competence Mediates The Relationship between Childhood Motor Skill Proficiency and Adolescent Physical Activity and Fitness: a Longitudinal Assessment. International journal of behavioral nutrition and physical activity, 5(1), 1 -12 .

Badrić, M., Prskalo, I., \& Matijević, M. (2015). Primary School Pupils' Free Time Activities. Croatian Journal of Education - Hrvatski časopis za odgoj o obrazovanje, 17, 299-319.

Branta, C., Haubenstricker, J., \& Seefeldt, V. (1984). Age Changes in Motor Skills During Childhood and Adolescence. Exercise and Sport Sciences Reviews, 12(4), 467-520. http:// dx.doi.org/10.1249/00003677-19840100000015.

Brown, T., \& Lalor, A. (2009). The Movement Assessment Battery for Children-Second Edition (MABC-2): A Review and Critique. Physical \& Occupational Therapy in Pediatrics, 29, 86103.

Carley, M. (2010). The Relationship Between Fundamental Motor Skill Development and Lifetime Participation in Physical Activity. PSAHPERD, winter, 31-33.

Cohen, K. E., Morgan, P. J., Plotnikoff, R. C., Callister, R., \& Lubans, D. R. (2014). Fundamental Movement Skills and Physical Activity among Children Living in Low-Income Communities: a Cross-sectional study. International Journal of Behavioral Nutrition and Physical Activity, 11(1), 49-58. http:// dx.doi.org/10.1186/1479-5868-11-49.

Fritz, C. O., Morris, P. E., \& Richler, J. J. (2012). Effect Size Estimates: Current Use, Calculations, and Interpretation. Journal of Experimental Psychology: General, 141, 2.

Foulkes, J. D., Knowles, Z., Fairclough, S. J., Stratton, G., O'dwyer, M., Ridgers, N. D., \& Foweather, L. (2015). Fundamental Movement Skills of Preschool Children in Northwest Eng- land. Perceptual and Motor skills, 121(1), 260283.

Haapala, E. A. (2013). Cardiorespiratory Fitness and Motor Skills in Relation to Cognition and Academic Performance in Children: A review. Journal of Human Kinetics, 36, 55-68.

Haibach-Beach, P., Reid, G., \& Collier, D. (2011). Motor Learning and Development (1st ed.). Champaign, IL: Human Kinetics.

Hardy, L. L., King, L., Farell, L., Macnivan, R., \& Howlett, S. (2010). Fundamental Movement Skills among Australian Preschool Children. Journal of Science and Medicine in Sport, 13 (5), 503-508. http://dx.doi.org/10.1016/ j.jsams.2009.05.010.

Henderson, S. E., Sugden, D. A., \& Barnett, A. L. (2007). Movement Assessment Battery for Children $-2^{\text {nd }}$ edition. London, United Kingdom: Harcourt Assessment.

Kokštejn, J., Musálek, M., \& Tufano, J. J. (2017). Are Sex Differences in Fundamental Motor Skills Uniform throughout The Entire Preschool Period?. PloS one, 12(4), e0176556.

LeGear M, Greyling L, Sloan E, Bell R, Williams B, Naylor P, et al. A Window of Opportunity? Motor Skills and Perceptions of Competence of Children in Kindergarten. Int $J$ Behav Nutr Phys Act. 2012; 9(1):29.

Liu, T., \& Breslin, C. M. (2013). The Effect of a Picture Activity Schedule on Performance of The MABC-2 for Children with Autism Spectrum Disorder. Research Quarterly for Exercise and Sport.

Livesey, D., Coleman, R., \& Piek, J. (2007). Performance on The Movement Assessment Battery for Children by Australian 3-to 5-year-old children. Child: care, health and development, 33 (6), 713-719

Logan, S. W., Robinson, L. E., Wilson, A. E., \& Lucas, W. A. (2012). Getting the Fundamentals of Movement: A meta-analysis of The Effectiveness of Motor Skill Interventions in Children. Child: Care, Health and Development, 38 (3), 305-315. http://dx.doi.org/10.1111/j.13652214.2011.01307.x

Magill, R.A. and K.G. Hall. (1990). A Review of The Contextual Interference Effect in Motor Skill Acquisition. Human Movement Science 9, 241-289.

Okely, A. D., Booth, M. L., \& Chey, T. (2004). Relationships between Body Composition and Fundamental Movement Skills among Children 
and Adolescents. Research Quarterly for Exercise and Sport, 75(3), 238-247. http:// dx.doi.org/10.1080/02701367.2004.10609157

Pate, R. R., Pfeiffer, K. A., Trost, S. G., Ziegler, P., \& Dowda, M. (2004). Physical Activity among Children Attending Preschools. Pediatrics, 114 (5), 1258-1263.

Piek, J. P., Dawson, L., Smith, L. M., \& Gasson, N. (2008). The Role of Early Fine and Gross Motor Development on Later Motor and Cognitive Ability. Human Movement Science, 27(5), 668 -681. https://doi.org/10.1016/j. humov.2007.11.002.

Pope, M. L., Liu, T., \& Getchell, N. (2011). ObjectControl Skills in Hispanic Preschool Children Enrolled in Head Start. Perceptual and Motor Skills, 112(1), 193-200.

Robinson, L. E. (2011). The Relationship between Perceived Physical Competence and Fundamental Motor Skills in Preschool Children. Child: care, health and development, 37(4), 589-596.

Singh, D. K. A., Rahman, N. N. A. A., Rajikan, R., Zainudin, A., Nordin, N. A. M., Karim, Z. A., \& Yee, Y. H. (2015). Balance and Motor Skills among Preschool Children Aged 3 to 4 years old. Malaysian Journal of Medicine and Health Sciences, 11(1), 63-68.

Shala, M. (2009). Assessing Gross Motor Skills of Kosovar Preschool Children. Early Child Development and Care, 179(7), 969-976.

Spessato, B. C., Gabbard, C., Valentini, N., \& Rudisill, M. (2013). Gender Differences in Brazilian Children's Fundamental Movement Skill Performance. Early Child Development and Care, 183(7), 916-923.

Stodden, D.F., Goodway, J.D., Langendorfer, S.J., Roberton, M.A., Rudisill, M.E., Garcia, C., \& Garcia, L.E. (2008). A Developmental Perspective on The Role of Motor Skill Competence in Physical. Activity: An Emergent Relationship. Quest, 60(2), 290-306. Retrieved from http:// journals.humankinetics.com/quest.

Stodden, D. F., Langendorfer, S., \& Roberton, M. A. (2009). The Association between Motor Skill Competence and Physical Fitness in Young Adults. Research Quarterly for Exercise and Sport, $\quad 80(2), \quad 223-229 . \quad$ http:// dx.doi.org/10.1080/02701367.2009.10599556.

Van Waelvelde H, Peersman W, Lenoir M, Smits Engelsman BC, Henderson SE. (2008). The Movement Assessment Battery for Children:
Similarities and Differences between 4- and 5year-old Children from Flanders and The United States. Pediatr Phys Ther. Spring; 20(1):308. doi: 10.1097/PEP.0b013e31815ee2b2. PMID: 18300931.

Venetsanou, F., \& Kambas, A. (2011). The Effects of Age and Gender on Balance Skills in Preschool Children. Facta universitatis-series: Physical Education and Sport, 9(1), 81-90.

Whyatt, C. P., \& Craig, C. M. (2012). Motor Skills in Children Aged 7-10 years, Diagnosed with Autism Spectrum Disorder. Journal of Autism and Development Disorders, 42, 1799-1809 